\title{
A UTILIZAÇÃO DA METODOLOGIA DE INVESTIGAÇÃO NO ENSINO DE BOTÂNICA: SUPERANDO LIMITAÇÕES DE FORMAÇÃO
}

\author{
Lucas Anibal Faria Seabra ${ }^{1}$
}

Barbara Cristina Heitor ${ }^{2}$

Antonio Fernandes Nascimento Junior ${ }^{3}$

\section{RESUMO}

A necessidade de metodologias de ensino que faça com que o aluno busque relacionar os fenômenos, fatos, pensamentos, deve ser estruturada para que o mesmo possua um pensamento concreto, capaz de compreender e questionar sobre os elementos naturais e sociais que fazem parte da sua história. Os professores são as bases necessárias para essa compreensão, sendo que os mesmos em grande escala possuem uma série de obstáculos para superar as limitações metodológicas e conceituais de formação existente no cotidiano escolar, fazendo-os recorrer aos livros didáticos de ensino. Como alternativa para o Ensino de Botânica a metodologia de investigação proposta neste trabalho, foi desenvolvida por dois alunos do curso de Ciências Biológicas Licenciatura onde cursavam a disciplina de Metodologia de Ensino em Botânica da Universidade Federal de Lavras. A proposta de tal disciplina, foi a criação de uma metodologia diferenciada para distanciando de elementos expositivos e acríticos, buscando uma compreensão e questionamento dos elementos que circundam o dia a dia dos alunos. Em momentos posteriores a mesma foi aplicada aos alunos da disciplina e a alunos do $7^{\circ}$ Ano do ensino fundamental da Escola Municipal Professor José Luiz de Mesquita, do município de Lavras-MG. Com analises e discussões sobre as avaliações em ambas aplicações, a pratica se mostrou potencializadora para o ensino de Botânica direcionado ao Reino Plante, onde é de fácil inserção para o contexto escolar, sendo uma metodologia de fácil aplicação e eficiente na construção de conhecimentos solidificados no dia a dia dos alunos.

\footnotetext{
${ }^{1}$ Graduando em Licenciatura em Ciências Biológicas, Universidade Federal de Lavras lucaspta1992@hotmail.com

2 Graduada em Licenciatura em Ciências Biológicas, Universidade Federal de Lavras barbara.cristina2810@yahoo.com.br

Professor Adjunto do Departamento de Biologia da Universidade Federal de Lavras toni nascimento@yahoo.com.br
} 


\title{
USE OF RESEARCH METHODOLOGY FOR THE TEACHING OF BOTANY: OVERCOMING LIMITATIONS OF TRAINING
}

\begin{abstract}
The need for teaching methodologies that make the student seeks to relate the phenomena, facts, thoughts, should be structured so that it has a concrete thinking, able to understand and ask about the natural and social elements that are part of its history. Teachers are needed for this understanding bases, with the same large scale have a number of obstacles to overcome methodological and conceptual limitations of existing training in school life, making them resort to textbook teaching. Alternatively for Teaching Botany the research methodology proposed in this paper, was developed by two students of Biological Sciences Degree which attended the course of Teaching Methodology in Botany, Federal University of Lavras. The purpose of such discipline, was the creation of a differentiated for distancing elements of expository and uncritical methodology, questioning and seeking an understanding of the elements that surround the daily lives of students In later times it was applied to students in the discipline and students from the 7th year of elementary school of the City School Professor José Luiz de Mesquita, the Lavras-MG. With analysis and discussions on the assessments in both applications, the practice proved aggravator for teaching Botany directed to United Plant, where it is easy to insert into the school context, and a methodology is easy to apply and effective in building knowledge solidified in the daily lives of students.
\end{abstract}

KEY-WORDS: Methodology. Teaching Botany. Teachers.

\section{USO DE METODOLOGÍA DE LA INVESTIGACIÓN PARA LA ENSEÑANZA DE LA BOTÁNICA: SUPERAR LAS LIMITACIONES DE FORMACIÓN}

\begin{abstract}
RESUMEN
La necesidad de metodologías de enseñanza que hacen que el estudiante busca relacionar los fenómenos, hechos, pensamientos, deben estructurarse de manera que tenga un pensamiento concreto, capaz de entender $y$ preguntar acerca de los elementos naturales y sociales que forman parte de su historia. Se necesitan maestros para estas bases de comprensión, con la misma gran escala tienen una serie de obstáculos para superar las limitaciones metodológicas y conceptuales de formación existente en la vida escolar, por lo que recurren a los libros de texto de enseñanza. Como alternativa para la Enseñanza de Botánica de la metodología de la investigación propuesta en este trabajo, fue desarrollado por dos estudiantes de Ciencias Biológicas Licenciatura que asistieron al curso de Metodología de la Enseñanza de Botánica de la Universidad Federal de Lavras. El propósito de tal disciplina, fue la creación de una diferenciada para alejar elementos de metodología expositiva y acrítica, el cuestionamiento y la búsqueda de la comprensión de los elementos que rodean la vida cotidiana de los estudiantes. En tiempos posteriores se aplica a los alumnos de la disciplina y estudiantes del séptimo año de la escuela primaria de la Escuela Ciudad profesor José Luiz de Mesquita, el Lavras-MG. Con el análisis y los debates sobre las evaluaciones en ambas aplicaciones, la práctica demostró agravante para la enseñanza de la botánica
\end{abstract}


dirigida al Reino Vegetal, donde es fácil de insertar en el contexto escolar, y una metodología de fácil aplicación y efectivo en la construcción del conocimiento solidificó en la vida cotidiana de los estudiantes.

PALABRAS-CLAVE. Metodología. La enseñanza de la botánica. Profesores.

\section{INTRODUÇÃO}

A classe do professorado enfrenta uma série de obstáculos para superar limitações metodológicas e conceituais de formação em seu cotidiano escolar. Lima e Vasconcelos 2006 relata que ao trabalhar os conteúdos,os educadores deparam-se com frágeis instrumentos de trabalho, o que pode gerar dependência ao uso do livro didático. Independente das metodologias ou estratégias pedagógicas, o ensino de Ciências deve proporcionar a todos(as) os(as) cidadãos(as) os conhecimentos e oportunidades de desenvolvimento, de capacidades necessárias para se orientarem em uma sociedade complexa, compreendendo o que se passa à sua volta, tomando posição e intervindo em sua realidade (Chassot, 2003).

Tendo em vista a elevada importância das plantas, a Botânica é reconhecida como uma das disciplinas da Biologia que deve ser ensinada no ensino fundamental $\mathrm{e}$ médio, permitindo ao aluno desenvolver as habilidades necessárias para a compreensão do papel do ser humano na natureza (BRASIL, 2006).

É real a necessidade de apresentar o conhecimento em botânica mediante estratégias mais dinâmicas e interativas, e assim permitir que o aluno relacione 0 assunto abordado com o seu cotidiano, construindo, de forma lógica e coerente o seu entendimento (COSTA, 2009).

Ceccantini (2006) e Trivelato (2003), afirmam que muitos professores de biologia fogem das aulas de botânica alegando ter dificuldade em desenvolver atividades práticas que despertem a curiosidade do aluno e mostrem a utilidade daquele conhecimento no seu dia-a-dia. O contato dos alunos com a diversidade dos seres vivos, baseada unicamente nas descrições morfológicas e fisiológicas de grupos biológicos, pode ser desastroso, chegando a desenvolver repúdio a todo este conhecimento e desvalorizando suas reais curiosidades acerca dos ambientes e seres vivos . 
Segundo as orientações dos Parâmetros Curriculares Nacionais (PCN), o tema 'meio ambiente' propõe que os estudantes sejam capazes de identificar-se como parte integrante da natureza e sentir-se afetivamente ligados a ela. Assim, os estudantes devem "perceber, apreciar e valorizar a diversidade natural adotando posturas de respeito aos diferentes aspectos e formas do patrimônio natural" (Brasil 1998).

\section{PERTINÊNCIA E OBJETIVOS DA PESQUISA}

Diante as afirmações e necessidades de um ensino fora dos padrões atuais acreditamos juntamente com o PCN, que a investigação e compreensão possa relacionar fenômenos, fatos, processos e idéias em Biologia, elaborando conceitos, identificando regularidades e diferenças, construindo generalizações onde possa utilizar critérios científicos para realizar classificações de animais, vegetais etc . Investigar na sala de aula proporciona ao professor e aos alunos liberdade de criação, utilização e comparação de uma ampla variedade de representações mentais, de conjectura e de métodos de resolução. Atualmente, a investigação é utilizada no ensino com a finalidade de:

- Promover desenvolvimento de habilidades cognitivas nos alunos;

- Realização de procedimentos como elaboração de hipóteses; anotação e análise de dados;

- O desenvolvimento da capacidade de argumentação. (ZOMPERO,2010)

Dessa maneira há a necessidade da realização de um trabalho em grupo onde o mesmo oferece benefícios como o desenvolvimento de habilidades de trabalho em equipe, aumento do interesse e da motivação dos estudantes, a possibilidade dos alunos aprenderem com os seus colegas, a oportunidade de experiências multiculturais ou de contextos sócio-econômicos distintos (Williams, Beard \& Rymer, 1991).Perante esses aspectos é necessário que o professor adote uma postura em que

- Atue como condutor, estimulador e avaliador da aprendizagem; 
- Auxilie o aluno na tarefa de formulação e de reformulação de conceitos, ativando seus conhecimentos prévios e articulando esses conhecimentos a uma nova informação que está sendo apresentada;

- Professor como problematizador, e mediador no processo ensinoaprendizagem.

\section{METODOLOGIA}

A metodologia de investigação proposta neste trabalho, foi desenvolvida por dois alunos do curso de Ciências Biológicas Licenciatura onde cursavam a disciplina de Metodologia de Ensino em Botânica da Universidade Federal de Lavras. A proposta de tal disciplina, foi a criação de uma metodologia diferenciada para o ensino dos diversos temas da botânica. Nesse sentido, a disciplina possuía momentos onde os alunos pensavam e embasavam suas metodologias, e momentos em que essas metodologias eram discutidas e refletidas com toda a turma a fim de proporcionar o amadurecimento da proposta. Ao final do semestre letivo, as metodologias eram apresentadas em forma de aula.

A metodologia de investigação foi proposta para o ensino de biodiversidade de plantas para alunos do ensino fundamental II, mas necessariamente o Reino Plante. Nesse sentido, entendeu-se que utilizar o cotidiano dos alunos seria um importante aliado para o sucesso da metodologia.

No primeiro momento, o docente deveria separar plantas pertencentes aos grupos das briófitas, pteridófitas, gimnospermas e angiospermas que fossem presentes no dia a dia dos alunos. É importante ressaltar, que o professor deve ter a cautela de escolher plantas que bem represente cada grupo ao qual elas pertencem, de forma que os alunos por meio da investigação possam enquadralas em um dos grupos. O professor deve também confeccionar 4 cartinhas (Figura 1) com as características das diferentes plantas. É importante que essas cartinhas tragam informações precisas, fáceis de se visualizar e que sejam capazes de instigar o aluno a investigar as plantas. 
A partir daí o professor deve orientar os alunos a dividirem-se em grupos, onde cada grupo receberá quatro plantas e três cartinhas de investigação. No decorrer da aula, com a mediação do docente, os alunos devem localizar suas plantas as cartinhas recebidas. Ao se encerrar essa primeira etapa, cada grupo terá uma de suas plantas sem correspondência nas cartinhas. Assim iniciasse um outro importante momento de interação entre a classe, cada grupo deve procurar nos outros grupos a cartinha que corresponde a sua planta restante.

Ao final, propõe-se uma discussão com toda turma, onde os alunos colocaram os motivos que os levaram a fazer tais correspondências. Nesse momento, o professor deve mediar para que todos os conhecimentos sejam abordados e aprofundados caso seja necessário.

Figura 1: Imagem das cartas a serem identificadas

\begin{tabular}{|c|c|}
\hline $\begin{array}{l}\text { Briófitas } \\
\text { *Plantas de lugares úmidos e algumas } \\
\text { espécies flutuam em água doce } \\
\text { *As mais antigas da Terra } \\
\text { *Temos como exemplos os Musgos,que } \\
\text { possuem } \\
\text { Rizoides, filoides e cauloides } \\
\text { *Não há vasos condutores } \\
\text { *Transporte da seiva feito de célula para } \\
\text { célula } \\
\text { *Reprodução assexuada e sexuada: } \\
\text { alternância de gerações }\end{array}$ & $\begin{array}{l}\text { Pteridófitas } \\
\text { *Plantas vasculares: com vasos } \\
\text { condutores } \\
\text { *Vivem melhor em ambientes úmidos e } \\
\text { pouco iluminados } \\
\text { *Possui raiz, caule e folha } \\
\text { *Não produz sementes, flores ou frutos } \\
\text { *Folhas jovens chamadas de Báculos } \\
\text { *Possui arquegônio e anterídio } \\
\text { * } \text { * Reprodução assexuada e sexuada: } \\
\text { alternância de gerações } \\
\text { *Xaxim (samambaia) }\end{array}$ \\
\hline $\begin{array}{l}\text { Gimnospermas } \\
\text { *Aparecimento de grãos de pólen } \\
\text { *Aonquista do ambiente terrestre pelos } \\
\text { *Cogetais } \\
\text { veget } \\
\text { *Possui raiz,caule e folha } \\
\text { *Não possuem frutos } \\
\text { *Possuem sementes nuas } \\
\text { *Exemplos: cipreste } \\
\text { * Reprodução assexuada e sexuada: } \\
\text { alternância de gerações } \\
\text { *Possuem estróbilos } \\
\text { *Resina: ÂMBAR }\end{array}$ & \begin{tabular}{l}
\multicolumn{1}{c}{ Angiospermas } \\
*Muito numerosos, encontrado em todo o \\
planeta \\
*Possuem flores, frutos e sementes \\
*Semente protegida pelo fruto \\
*Ovário se desenvolve em fruto \\
*Possuem vasos condutores de seiva \\
*Monocotiledôneas e dicotiledôneas.
\end{tabular} \\
\hline
\end{tabular}

Fonte: Seabra,L,A,F. 2014. 


\section{A APLICAÇÃO DA METODOLOGIA}

A metodologia de investigação, foi apresentada em dois momentos distintos. O primeiro foi ao final da disciplina de Metodologia de Ensino em Botânica (Figura $2 \mathrm{e}$ 3). Nesse espaço ela foi apresentada de forma resumida em uma aula. Logo após o encerramento, os alunos das disciplinas faziam suas contribuições e reflexões a respeito dos potenciais oferecidos pela investigação.

Figura 2 e 3: Ministração da Aula no final da disciplina
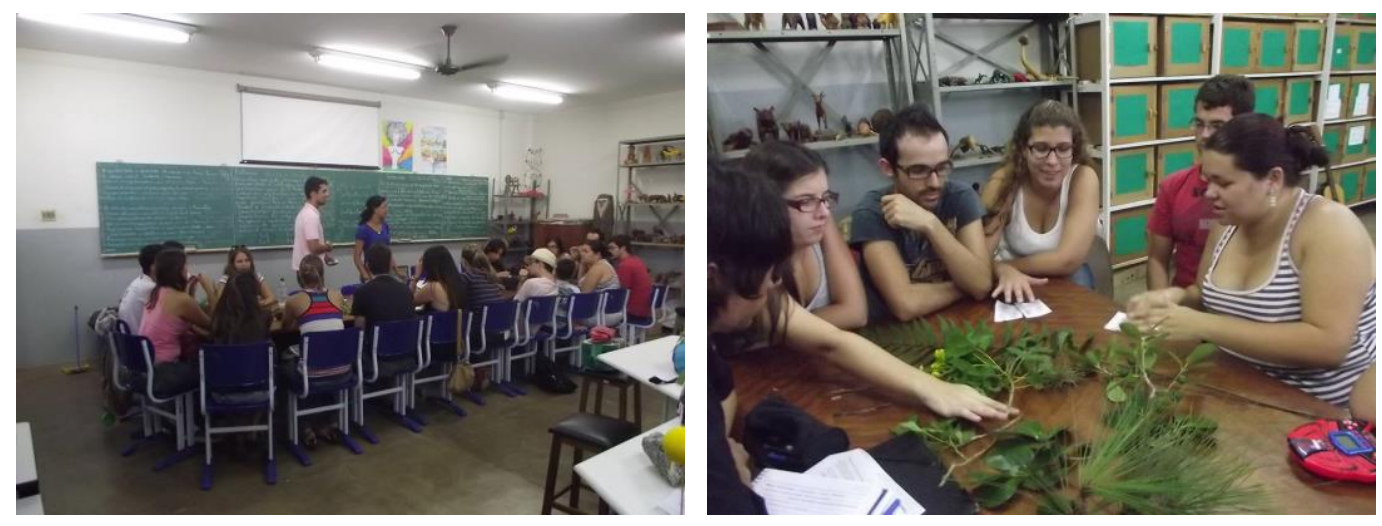

Fonte: Seabra,L,A,F. 2014.

A segunda aplicação da metodologia, aconteceu com alunos do $7^{\circ}$ Ano do Ensino fundamental da Escola Municipal Professor José Luiz de Mesquita, do município de Lavras-MG. Na escola a atividade teve duração de 2 aulas de 50 minutos, e contou com o auxilio da professora de ciências responsável pela turma (Figura 4 e 5). 
Figura 3 e 4: Apresentação da aula para alunos do Ensino Fundamental
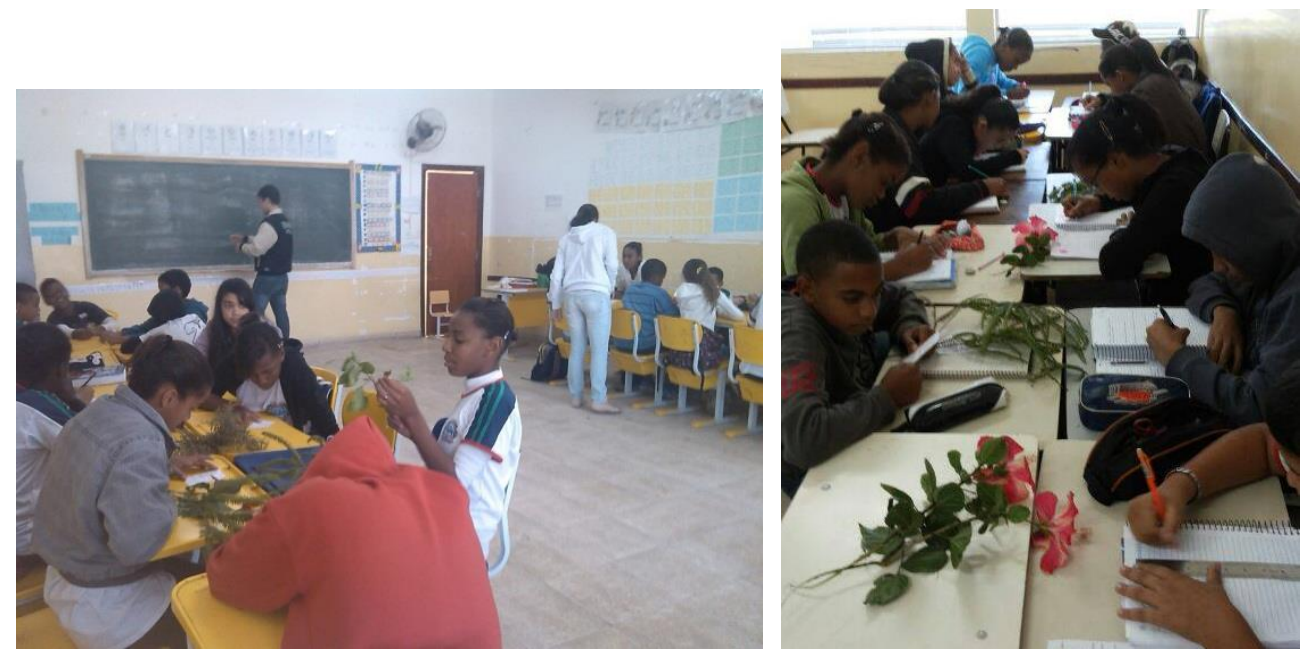

FONTE: SEABRA,L,A,F. 2014.

Nesta aplicação as turmas eram dividas em dois grupos proporcionando que a atividade fosse desenvolvida em grupo. Após acontecer a identificação das plantas que fazem parte do cotidiano dos alunos, houve uma redistribuição em duplas ou trios para que os termos em negrito de cada carta fosse distribuído aos alunos e os mesmos deveriam apresenta-los em uma próxima aula. A apresentação não necessitaria de pesquisas, pois houve uma preocupação para que nos diálogos de identificação das plantas houvesse uma abordagem dos termos. Esse momento serviria como método avaliativo da estratégia.

\section{RESULTADOS}

A metodologia foi apresentada aos alunos e ao professor da disciplina, onde houve um espaço aberto para contribuições ao trabalho. A atividade foi gravada e algumas das falas dos participantes foram transcritas a fim de discutirmos alguns aspectos referentes as mesmas. Os participantes serão identificados com a letra P. 
Principais falas que permearam a discussão na disciplina:

P1: A aula de vocês foi boa. Gostei bastante só tenho algumas coisas pra falar. Primeira coisa que eu achei é que nas cartinhas não precisava ter dado tanto detalhe das palavras em si sabe. Não precisava ter colocado estróbilo ou esporófito esses termos mais complicados, e focar mais no que é visível mesmo, no que da pro menino ver ali na planta que eu acho que seria bem mais fácil....esse aspecto de integrar a turma em dois grupos e trabalhar com esses dois grupos conflitando o que um grupo achou aqui e o que o grupo de lá acho. Isso é muito bom e muito válido.

P2: Gostei muito também achei que deu pra todo mundo identificar todos os grupos. não teve muita dificuldade muito problema com isso Eu achei um pouquinho difícil só a parte dos vasos porque tem planta tipo essa que não dá pra ver vaso nenhum, então as vezes escolher uma planta que dê pra ver. Mais ai no final você explicou certinho que é tipo nossas veias, deu pra entender. Gostei muito P3: A ideia de vocês trazerem o material pra dentro da sala de aula é bem legal, no meu ponto de viste desperta mais ainda o interesse do aluno em estar pegando o material estar tocando e estar precisando ali naquele momento, do que ficar só na parte teórica ali maçante. Só algumas coisinhas nos cartõezinhos tem que ser revistas tipo dos vasos como já foi dito.

P4: Ficou tudo muito bom e muito claro. Realmente foi uma coisa que a gente discutiu no grupo essa história dos termos muito complicados. Depende ne talvez pra $6^{\circ}$ ano sim e pra $8^{\circ}$ ano nem tanto. È muito de série mesmo assim, tem série que não vai entender e tem série que vai acho valido sim dependendo do pra quem for, como a gente costuma dizer depende do público alvo....

P5: Trazer para o aluno o palpável vai ser bem interessante pra que eles tenham vontade de aprender.inclusive mesmo os nomes mais complicados assim de cara pode estranhar ele olhar o nome e falar nossa nunca vi isso não sei, mais vocês explicarem assim tão bem explicado como foi... P6: Achei interessante a questão trazer as plantas que estão próximas, você trazer as plantas que os alunos está mais acostumado então a escolha das plantas foi pertinente. Achei a ideia de na cartinha trazer mais coisas que o aluno está vendo e depois chegar com o conceitos, as vezes ficaria melhor. P7: Uma coisa que eu vejo é que a gente tem que abordar certas partes da matéria que são complicadas. E é sempre difícil pensar em um jeito de abordar aquilo de forma que os alunos vão entender. Tem coisa que não tem jeito é realmente complicado e é difícil de ver como nesse cartão que tem coisas específica. E por mais que você tente uma ou outra coisa a gente tem que explicar mesmo. E eu acho que pra dar uma aula legal é preciso ter boa vontade, então vocês tiveram boa vontade e as pessoas veem que vocês se esforçaram.

P8: Trazer interação entre aluno aluno e aluno e professor é sempre muito bom. E eu só falo pra vocês reverem as cartinhas.

P9: Trazer material é muito interessante porque as vezes a gente passa do lado das plantas e nem presta atenção nelas, então achei muito legal e os alunos vão gostar bastante. E a questão das cartinhas na hora de identificar exige um pouco mais desse conhecimento mais só que gerar a dúvida 
é sempre valido e mesmo que o aluno pergunte pra você o que é estróbilo, eu acho interessante porque ai você vai perguntar "Mais o que você acha que é estróbilo?" e ai você vai trazer o conhecimento prévio e depois trazer o conceito. Então eu não acho um ponto negativo. Talvez mostrar primeiro o que se vê e depois trazer o nome realmente do que é mais não deixar de trazer esses nomes porque é necessário.

P10: Muito interessante as formas que vocês abordaram, principalmente por trazer as plantas que estão próximas dos alunos. Só que eu achei que vocês poderiam explorar mais os conhecimentos dos alunos, de onde você já viu essa planta? talvez seja mais fácil de se explicar porque ela consegue ficar em cima do muro, porque a gimnosperma não tem flor e a angiosperma tem flor. Porque pode ser um tipo de pergunta que apareça lá. Issó pra mim iria facilitar bastante no hora da discussão. Outra coisa é que um bocado do conhecimento prévio que vocês buscaram foi durante a mediação, durante as cartinhas. Eu acho que se vocês pudessem trazer esse conhecimento um pouquinho antes não tão específico e depois trazer o específico seria mais enriquecedor. A mediação foi muito interessante, concordo que as cartinhas com os termos são coisa que a gente consegue fazer muito bem como os vasos condutores e as veias e a gente consegue trazer isso pra mais perto.

P11: Trazer as plantas é muito bom que dá pra associar com o que ta escrito, e as vezes é planta que eles veem no dia a dia e não consegue fazer essa associação porque só vê a planto no livro na figura e não consegue perceber que é a mesma que está em casa. As cartinhas algumas coisa a gente achou meio difícil só que você explicou que com mais aulas vocês iriam explicar.

P12: Um aspecto importante, é que alem de vocês terem trago a planta pra gente visualizar vocês procuraram trazer plantas diferentes, por exemplo, tem flores diferentes, é o mesmo grupo mais são exemplares diferentes e frutos diferentes. Então eu acho isso importante já que o tema é biodiversidade. Vocês trouxeram coisas diferentes pra especificar o mesmo grupo. E das cartas normalmente a primeira vez que a gente vê as palavras e não conhece é não sabe o que é muito bem, mais com o passar do tempo a gente vai entendendo melhor e assimilando ainda mais com a explicação e com o material nas mãos.

P13: Eu achei muito interessante por ter um aspecto mais práticos do aluno conseguir ver e conhecer a coisa primeiro pra depois entrar em detalhes específicos como classificação e essas características mais particulares de cada grupo. Quanto aos termos eu acho igualmente importante, tem que mantêlos mais eu concordo que é interessante construir a ideia do que é primeiro e depois nomear. Acho que isso facilita a construção do aluno no momento em que ele ta ali observando e vendo se mostrar pra ele o que é e depois dar nome talvez seja mais fácil. Não que o caminho de facilidade seja o mais objetivo mais talvez seja mais eficaz. Pra mim isso é mais seguro.

X Fórum Ambiental da Alta Paulista, v. 10, n. 6, 2014, pp. 85-98 
A avaliação com os alunos da Escola Municipal Prof. José Luiz de Mesquita aconteceu por meio de um relato individual, sendo alguns deles citados abaixo:

P1: Foi muito bom o dia que o Lucas veio na sala. Ele dividiu a sala em 2 grupos e colocou várias plantas sobre a mesa. Colocou musgo, samambaia, pinheiro, colocou hibisco(flor vermelha), margarida (flor amarela). Ele também colocou papeizinhos na mesacom as características das plantas e tinha que juntar os papeizinhos com a planta correta como: musgo-briófita, samambaias-pteridófitas etc. Depois ele passou no quadro uma pesquisa pra gente fazer sobre as plantas, estou aprendendo muito com isso e estou super feliz por isto.

P2: A matéria que o Lucas passou explicando sobre flores estava muito bom. Ele explicou tudo sobre Angiospermas e Gimnospermas. Ele falou também dos musgos das samambaia, do cipreste e do Hibisco. Eu peguei os musgos mas eles não tinha cheiro. Também peguei as samambaias e os cipreste. Ele chegou e pediu para dividir a sala em grupos. E começou explicar sobre as plantas. E depois colocou nas mesas.

P3: No dia que o Lucas foi nosso prof ele separou a sala de aula em 2 grupos metade do meio para a direita e metade para a esquerda. Ele deu alguns papeis pequenos para a gente descobrir qual era a planta e a gente conheceu bastante plantas, como pinheiro, musgo, samambaia, cipreste, hibisco e foi muito bom. Com eles a gente aprende muita coisa e é muito engraçado de vez enquando ele leva a gente na horta, é bom aproveitar a vida com a floresta, alimentos e plantas e algumas tem cor e cheiro outras não isso que eu tenho para dizer.

P4: O Lucas veio aqui na escola e pediu para nós fazer dois grupos. Deu umas folhinhas para nós conhecemos as plantas melhor. Ai nós fizemos um quadro com Briófitas, Pteridófitas, Gimnosperma, Angiosperma e foi uma aula muito legal.

\section{UM POUCO DE DISCUSSÃO}

Ao analisar a falar dos participantes foi possível perceber a eficácia ao utilizar os elementos que permeiam a vida dos estudantes como descreve o P3 e o P6 do primeiro quadro. De acordo com P1 e o P4 do segundo quadro a pratica é legal ou seja através destes relatos conseguimos verificar a eficiência na construção do conheciemento no distanciamento de praticas expositivas e conteudistas.

De acordo com Pivelll (2005), estabelecer um contato direto com a diversidade encontrada na natureza pode ser o meio mais eficaz de aumentar o conhecimento e sensibilizar as pessoas de modo a proporcionar uma religação do ser humano com 
seu meio natural. Muita das vezes as plantas utilizadas fazem parte do caminho dos estudantes para a escola e os professores devem estar atentos naquilo que é próximo e palpável para os estudantes, sendo o dialogo fortalecido através dessas praticas. $O$ Brasil é líder mundial em diversidade de plantas, e conhecê-la faz com que tenhamos a responsabilidade de conservar muitas das espécies, ecossistemas naturais e processos biológicos que tornam o nosso planeta habitável (LEWINSOHN; PRADO, 2002).

É necessário que se forme uma consciência transformadora e crítica sobre os conhecimentos que nos são apresentados. Nosso país como líder em diversidade, deveria os habitantes saber questionar e cobrar das autoridades políticas ações que busquem cada vez mais uma preservação da biodiversidade existente. Para isso o conhecimento construído desse ser próximo daquilo que nos rodeia, sendo essa construção real desde os anos escolares fundamentais.

\section{CONCLUSÃO}

Após a aplicação da aula foi possível concluir que a metodologia se mostrou eficaz no processo de ensino e aprendizagem. A partir das discussões percebeu-se o grande potencial que a prática mostrou no que diz respeito em resgatar o conhecimento prévio dos alunos. Quanto as falas dos participantes da disciplina a prática foi considerada válida e capaz de alcançar os objetivos propostos, rompendo barreiras e superando as limitações metodológicas para o ensino de botânica.

\section{REFERÊNCIAS}

BRASIL. Secretaria de Educação Fundamental. Parâmetros curriculares nacionais: ciências naturais. Brasília: MEC/SEF, 1998.

CECCANTINI, G. Os tecidos vegetais têm três dimensões. Revista Brasileira de Botânica. São Paulo. v. 29, n. 2. 2006.

CHASSOT, A.. Alfabetização científica: uma possibilidade para a inclusão social. Revista Brasileira de Educação, 2003 22,89 p. 
COSTA, M. V. Aprendendo sistemática vegetal: hipertexto auxiliando na aprendizagem de botânica. Dissertação.UFMGS: Campo Grande, 2011, 40 p.

LEWINSOHN, T. M; PRADO P. I. Biodiversidade Brasileira Síntese do Estado Atual do Conhecimento. São Paulo: Contexto Acadêmica, 2002.10 p.

LIMA, K. C. ; VASCONCELOS, S. D. Análise da metodologia de ensino de ciências nas escolas da Rede Municipal do Recife. Ensaio. Avaliação e Políticas Públicas em Educação, v. 14, 2006 p. 397411.

MINISTÉRIO DA EDUCAÇÃO/BRASIL. Secretaria de Educação Média e Tecnológica. Orientações Curriculares para o Ensino Médio: Ciências da Natureza, Matemática e suas Tecnologias. Brasília: MEC/SEF, 2006.

PIVELLI, P.R.S.; KAWASAKI, S.C. Análise do potencial pedagógico de espaços não formais de ensino para o desenvolvimento da temática da biodiversidade e sua conservação. Associação Brasileira de Pesquisa em Educação em Ciências atas do V ENPEC - № 5. 2005 - ISSN 1809-5100 www.faculdadefortium.com.br/ana_karina/material/O\%20Ensino\%20De\%20Ciencias\%20Naturais $\% 20$ Nas\%20Series\%20Iniciais.doc. 